\title{
Ganaya:
}

Jurnal Tlme Sasial dan \#umaniara Jayapangus Press

http://jayapanguspress.penerbit.org/index.php/ganaya Vol. 4 No. 2 (2021)

\section{Social Media Activity dan Customer Experience dalam Membentuk Relationship Quality}

\author{
Barbara Suha $^{1}$, Kurnia ${ }^{2}$ \\ ${ }^{12}$ Public Relations, STIKOM InterStudi, Jakarta \\ barbarasuha3007@gmail.com
}

\begin{tabular}{l}
\hline Keywords: \\
\hline Customer \\
Experience, \\
Insurance \\
Company, \\
Relationship \\
Quality, Social \\
Media Activity \\
\hline
\end{tabular}

Kata Kunci:

Pengalaman

Konsumen,

Perusahaan

Asuransi,

Kualitas

Hubungan,

\begin{abstract}
Social media activities and positive user experiences are very important for Public Relations (PR) strategy in three aspects, namely as a media for presentation, communication, and improving PR performance, where social media activities that can be in line with users' positive experiences will be able to function to show organizational identity, create communication, direct decision making and improve the organization's mutual relationship strategy with its publics. This study aims to understand the relationship between social media activity and customer experience in establishing relationship quality which is implemented in specific insurance companies through a study approach at PT Asuransi Jiwa Astra, which was later known as Astra Life. This research method uses a quantitative approach using the positivism paradigm. The research population is Astra Life's active customers and 100 respondents are assigned as a representative sample. Data were collected through an online survey and analyzed using the Partial Least Square (PLS) method. The results of the study indicate that Social Media Activity and Customer Experience have a positive effect in shaping Relationship Quality. The results of this study also show that Social Media Activity and Customer Experience are very strong in explaining the success of Astra Life's PR Relationship Quality strategy approach with customers so that further research can also identify Social Media Activity and Customer Experience approaches in building Relationship Quality in similar service industries in order to obtain findings. the benefits of research in the field of communication Public Relations are more diverse.
\end{abstract}

\begin{tabular}{l} 
Abstrak \\
\hline Aktivitas sosial media dan pengalaman positif penggunanya \\
sangat penting bagi strategi Public Relation (PR) dalam tiga \\
aspek yaitu sebagai media presentasi, komunikasi, dan \\
meningkatkan kinerja PR, dimana aktivitas media sosial yang \\
dapat sejalan dengan pengalaman positif pengguna akan dapat \\
difungsikan untuk menunjukkan identitas organisasi,
\end{tabular}


Aktivitas Sosial

Media menciptakan komunikasi, mengarahkan pengambilan keputusan dan meningkatkan strategi mutual relationship organisasi dengan publiknya. Penelitian ini bertujuan untuk memahami hubungan Social Media Activity dan Customer Experience dalam membentuk Relationship Quality yang diimplementasikan pada perusahaan asuransi yang spesifik melalui pendekatan studi pada PT Asuransi Jiwa Astra yang kemudian dikenal dengan Astra Life. Metode penelitian ini menggunakan pendekatan kuantitatif dengan menggunakan paradigma positivism. Populasi penelitian adalah nasabah aktif Astra Life dan ditetapkan 100 responden sebagai sampel yang mewakili. Data dikumpulkan melalui survei online dan dianalisis menggunakan metode Partial Least Square (PLS). Hasil penelitian menunjukkan bahwa Social Media Activity dan Customer Experience berpengaruh positif dalam membentuk Relationship Quality. Hasil penelitian ini juga menunjukkan bahwa Social Media Activity dan Customer Experience sangat kuat dalam menjelaskan keberhasilan pendekatan strategi PR Reltionship Quality Astra Life dengan nasabah sehingga penelitian selanjutnya juga dapat mengidentifikasi pendekatan Social Media Activity dan Customer Experience dalam membangun Relationship Quality pada industri jasa sejenis agar diperoleh temuan manfaat penelitian di bidang komunikasi Public Relations yang lebih beragam.

\section{Pendahuluan}

Dalam public relations konsep publik berkaitan dengan penerima, khalayak, pemangku kepentingan, massa, pasar, kelompok sasaran, serta ruang publik yang menjadi banyak kajian komunikasi strategis terkait bagaimana menyampaikan informasi, menciptakan komunikasi, membangun hubungan untuk membentuk persepsi maupun perilaku positif terhadap organisasi maupun perusahaan (Grunig \& Hung, 2015). Grunig dan Hunt (1984) mengembangkan empat model Public Relations (PR) yang meliputi publisitas, informasi publik, komunikasi persuasif, dan model komunikasi dua arah sebagai strategi komunikasi PR (dalam Martinelli, 2020).

Strategi public relations idealnya dapat disesuaikan dengan pola dan tren komunikasi sosial agar dapat membangun kualitas hubungan dengan publik secara relevan (Shamsan \& Otieno, 2014). Hubungan masyarakat dan bentuk komunikasi strategis lainnya dapat dikontrol, diarahkan, ataupun terbentuk dengan sendirinya dan berdampak pada perilaku ataupun perspektif tertentu (Kim et al., 2015). Komunikasi strategis pada setiap media harus dipahami berdasarkan persepsi audiens pengguna media 
tersebut karena setiap media komunikasi memiliki pola dan bentuk interaksi yang berbeda (Gardiola \& Kurnia, 2020).

Dampak dari perkembangan teknologi komunikasi dan informasi menimbulkan perubahan pola komunikasi dan pola hubungan yang membuat masyarakat terbiasa untuk berinteraksi (berkomunikasi maupun berhubungan) secara digital dengan memanfaatkan beragam platform, di antaranya media sosial (Kurniawati \& Arifin, 2015). Perkembangan komunikasi digital menjadikan sosial media sebagai bentuk media baru yang mulai dimanfaatkan sebagai online public relations untuk mempublikasikan dan mengontrol informasi, mempersuasi serta membangun hubungan timbal balik secara virtual dengan publik secara lebih efisien, interaktif, dan personal (Reitz, 2012).

Media sosial memiliki karakteristik diantaranya bersifat partisipatif; adanya interaksi dua arah dari setiap penggunanya; komunikasi bersifat terbuka; siapapun dapat mengakses dan memanfaatkan isi pesan; Dialogis, yaitu adanya perbincangan antar pengguna secara dua arah; Relasional yaitu memungkinkan terbentuknya hubungan antar penggunanya (Juditha, 2017). Karakteristik tersebut membuat media sosial banyak dimanfaatkan oleh perusahaan untuk menciptakan komunikasi dan hubungan baik dengan pelanggan (Wibowo et al., 2020).

Penggunaan media sosial sangat penting bagi praktisi PR dalam tiga aspek yaitu sebagai media presentasi, komunikasi, dan meningkatkan kinerja PR, dimana akrivitas media sosial dapat difungsikan untuk menunjukkan identitas organisasi, menciptakan komunikasi serta meningkatkan kinerja kualitas hubungan organisasi dengan publiknya (Cheng, 2019). Praktisi PR yang mampu menyesuaikan perkembangan komunikasi di media sosial akan dengan mudah memahami publiknya sehingga memiliki banyak kesempatan untuk mengarahkan pengambilan keputusan dan meningkatkan strategi mutual relationship organisasi (Bhargave, 2010).

PT Asuransi Jiwa Astra (Astra Life) merupakan salah satu perusahaan asuransi jiwa yang memanfaatkan penggunaan media sosial sebagai communication and customer relationship media. Head of Direct Sales PT Asuransi Jiwa Astra Life, Bapak Rony Nainggolan menjelaskan bahwa media sosial memegang peran penting dalam mengarahkan komunikasi dan hubungan perusahaan dengan para customer sehingga dapat meningkatkan produktivitas pelayanan, bahkan terhitung saat pandemik Covid-19, potensi customer PT Asuransi Jiwa Astra (Astra Life) menunjukkan peningkatan sebesar 44\% (Annual Report PT Asuransi Jiwa Astra), Periode Februari 2020-2021). Namun hal 
ini tentu membawa tantangan baru bagi PT Asuransi Jiwa Astra (Astra Life) untuk dapat mempertahankan dan meningkatkan hubungan dengan pelanggannya sehingga komunikasi yang terjalin dapat meningkatkan profitabilitas perusahaan.

Kualitas hubungan (Relationship Quality) sangat penting untuk dapat meningkatkan profit dan keberlangsungan perusahaan khususnya bagaimana hubungan dengan customer dapat terbentuk berdasarkan pengalaman (Customer Experiance) nyata dan penilaian melalui adanya kepercayaan, kepuasan, dan komitmen (Wibowo et al., 2020). Kualitas hubungan (Relationship Quality) merupakan bentuk kesediaan, kepercayaan, komitmen dan kesinambungan hubungan jangka panjang antara customer dengan perusahaan (Zhang, 2011). Relationship Quality dalam media sosial dapat dinilai dari kekuatan hubungan antara customer dengan konten media sosial yang ditunjukkan dengan kesediaan customer untuk terbuka, bekerjasama dan menjalin kontak intensif dengan aktivitas media sosial kita (Chen \& Lin, 2015).

Customer Experience adalah pengalaman customer pada proses interaksi dengan produk ataupun layanan yang dapat terbentuk melalui bagaimana customer merasakan produk atau layanan secara fisik (sense), bagaimana perasaan customer menggunakan produk atau layanan secara fisik ( $f e e l$ ), seberapa jelas customer memahami manfaat produk (think), bagaimana produk atau layanan dapat menghubungkan pelanggan dengan orang lain, atau dengan hal-hal yang kemungkinan mereka temui mendatang (relate) serta bagaimana produk dapat memotivasi customer untuk dapat memiliki sikap positif terhadap produk (Act) (Izogo, 2018). Dalam menciptakan hubungan melalui pengalaman pelanggan, media sosial saat ini berperan sebagai online public relation yang berfungsi untuk mengarahkan, mempengaruhi, dan berinteraksi dengan khalayak secara personal dengan pemanfaatan fitur konten maupun tampilan visual (Carr et al., 2015).

Customer experience bertujuan untuk menjaga perubahan perilaku pelanggan dan berfungsi mempertahankan komitmen kesediaan pelanggan (Hsu et al., 2011). Kulitas hubungan merupakan sebuah komitmen yang terbentuk dari upaya perusahaan dalam menjaga hubungan melalui aktivitas yang diarahkan guna menciptakan persepsi, kesan dan penilaian yang positif terhadap publik (Wibowo et al., 2020). Maka, dapat dihipotesiskan bahwa:

H1: Social Media Activity berpengaruh positif terhadap Relationship Quality

H2: Customer Experience berpengaruh positif terhadap Relationship Quality 
Berdasarkan uraian dan hipotesis yang diajukan tersebut, penelitian ini bertujuan untuk memahami aktivitas media sosial (Social Media Activity) dan pengalaman pelanggan (Customer Experience) dalam membentuk hubungan yang berkualitas (Relationship Quality) melalui studi kasus pada PT Asuransi Jiwa Astra (Astra Life).

\section{Metode}

Penelitian ini dilakukan melalui pendekatan kuantitatif dengan menggunakan paradigma positivistik. Pengumpulan data menggunakan distribusi kuesioner online dengan pengukuran skala likert skor 1 sampai 5 mulai dari sangat tidak setuju (STS), tidak setuju (TS), ragu-ragu (RR), setuju (S), sangat setuju (SS). Populasi dalam penelitian ini adalah nasabah PT Asuransi Jiwa Astra (Astra Life) pada masa pandemi Covid-19 terhitung dari periode Februari 2020 sampai dengan Februari 2021 dengan total 1.847 nasabah. Berdasarkan perhitungan rumus Slovin, diperoleh 100 nasabah sebagai sampel penelitian yang ditentukan dengan teknik non-probability sampling. Kriteria responden dalam penelitian ini adalah customer aktif yang memiliki polis Astra Life dan mengikuti informasi yang diposting pada media sosial Astra Life. Hal tersebut diketahui dari pertanyaan saringan kepada responden untuk dapat menjawab pertanyaan selanjutnya.

Kuesioner penelitian disusun dengan mengadopsi skala item Wibowo (2021) yang terdiri dari 11 item pertanyaan variabel Social Media Activity, 12 item pertanyaan variabel Customer Experience, 10 item pertanyaan variabel Relationship Quality yang disebarkan melalui email dan WA yang diperoleh dari bagian Customer Astra Life. Analisis data dilakukan dengan Structural Equation Modeling (SEM) menggunakan Partial Least Square (PLS).

\section{Hasil dan Pembahasan}

Responden dalam penelitian ini merupakan customer yang telah membeli polis Astra Life dan mengikuti digital platform Astra Life, seperti media sosial dan website. Usia responden didominasi usia kisaran diatas 32 tahun sebanyak 46,7\%, sedangkan $23.4 \%$ adalah responden dengan usia kisaran $28-32$ tahun dan $29.9 \%$ berusia 25 tahun. Hal ini menunjukkan bahwa responden yang aware dengan informasi terkait asuransi umumnya adalah responden dengan kisaran usia di atas 25 tahun. Responden penelitian 
ini terdiri atas perempuan sebanyak $57.9 \%$ dan laki-laki sebanyak $42.1 \%$ yang menggunakan media sosial antara $2-4$ jam sehari (34.6\%).

Hasil pengukuran model (tabel 1) menunjukkan bahwa masing-masing indikator pada setiap variable X dan Y memiliki nilai Average Variance Extracted (AVE) yang lebih tinggi dari 0,50 sehingga dapat dipastikan bahwa seluruh indikator penelitian telah valid (Boonlertvanich, 2019). Hasil Composite Reliability (CR) masing-masing variabel melebihi 0,70 yang menandakan bahwa keseluruhan variabel teruji reliabilitasnya (Cakici et al, 2019).

Tabel 1. Hasil Uji Validitas dan Reliabilitas

\begin{tabular}{lccc}
\hline Variable & Mean & $\begin{array}{c}\text { AVE } \\
(>\mathbf{0 . 5 0})\end{array}$ & $\begin{array}{c}\text { CR } \\
(>\mathbf{0 . 7 0 )}\end{array}$ \\
\hline CE & 3.859 & 0.607 & 0.915 \\
\hline RQ & 3.937 & 0.620 & 0.942 \\
\hline SMA & 3.840 & 0.654 & 0.944 \\
\hline
\end{tabular}

Note: SMA (Social Media Activity), CE (Customer Experience), RQ (Relationship Quality), AVE (Average Variance Extracted), CR (Composite Reliability)

\begin{tabular}{lcccc}
\hline Matriks & $\begin{array}{c}\text { Cronbach's } \\
\text { Alpha }\end{array}$ & rho_A & $\begin{array}{c}\text { Composite } \\
\text { Reliability }\end{array}$ & $\begin{array}{c}\text { Average Variance } \\
\text { Extracted }\end{array}$ \\
\hline CE & 0.891 & 0.895 & 0.915 & 0.607 \\
\hline RQ & 0.932 & 0.932 & 0.942 & 0.620 \\
\hline SMA & 0.934 & 0.936 & 0.944 & 0.654 \\
\hline
\end{tabular}

Nilai Koefisien Determinasi $\left(\mathrm{R}^{2}\right)$ dalam penelitian ini yang tertera pada tabel 2 sebesar 0,721 menunjukkan bahwa Relationship Quality 72,1\% dengan kuat dijelaskan oleh variabel Social Media Activity dan Customer Experience secara bersama, sedangkan $27,9 \%$ sisanya dijelaskan oleh variabel lain di luar penelitian ini.

Hasil pengujian hipotesis (Tabel 2) menunjukkan bahwa Social Media Activity (T Stat $=3.425, \beta=0.425, p=0.000)$ dan Customer Experience $(\mathrm{T}$ Stat $=8.719, \beta=0.719$, $\mathrm{p}=0.000)$ juga terbukti signifikan berpengaruh positif terhadap Relationship Quality.

Tabel 2. Uji Hipotesis

\begin{tabular}{ccccc}
\hline Hypothesis & Coefficient & T Statistic & P Values & Result \\
\hline $\begin{array}{c}\text { H1 } \\
\text { SMA -> RQ }\end{array}$ & 0.425 & 3.425 & 0,000 & Support \\
\hline $\begin{array}{c}\text { H2 } \\
\text { CE - RQ }\end{array}$ & 0.719 & 8.719 & 0,000 & Support \\
\hline \multicolumn{5}{c}{$\mathrm{R}^{2}: 0,721(72,1 \%)$} \\
\hline
\end{tabular}

Note: SMA (Social Media Activity), CE (Customer Experience), RQ (Relationship Quality) 
Model hasil penelitian (Gambar 1) menunjukan bahwa Customer Experience memiliki pengaruh yang paling besar $(\beta=0.719)$ dalam membangun Relationship Quality. Temuan ini juga didukung dengan hasil data deskriptif yang menunjukkan nilai mean tertinggi variabel independen berada pada mean variabel Customer Experience (3.89) yang menjelaskan bahwa media sosial Astra Life sesuai dengan aktivitas yang customer lakukan menjadi faktor utama yang membuat Relationship Quality. Temuan ini memperkuat dan mendukung hasil temuan Wibowo et al. (2020) bahwa kualitas hubungan merupakan merupakan sebuah komitmen yang terbentuk dari upaya perusahaan dalam menjaga hubungan melalui aktivitas yang diarahkan untuk menciptakan persepsi, kesan dan penilaian yang positif bagi publiknya.

Selanjutnya, Social Media Activity menjadi variabel kedua yang membangun Relationship Quality $(\beta=0,425)$. Sekalipun nilai rata-rata mean variabel kepuasan pelanggan berada di bawah variabel Relationship Quality, mean indikator variabel ini masih dalam rentang skala yang relatif tinggi sehingga dapat dinyatakan bahwa upaya PT Astra Life dalam mengoptimalkan Social Media Activity melalui konten yang menarik dan informatif juga turut menjadi faktor yang membuat penjualan polis meningkat pada bulan Maret 2020 dan bulan berikutnya serta membentuk Relationship Quality yang baik antara nasabah dengan perusahaan yang diketahui dari comment positif dari para nasabah yang ada di postingan media sosial.

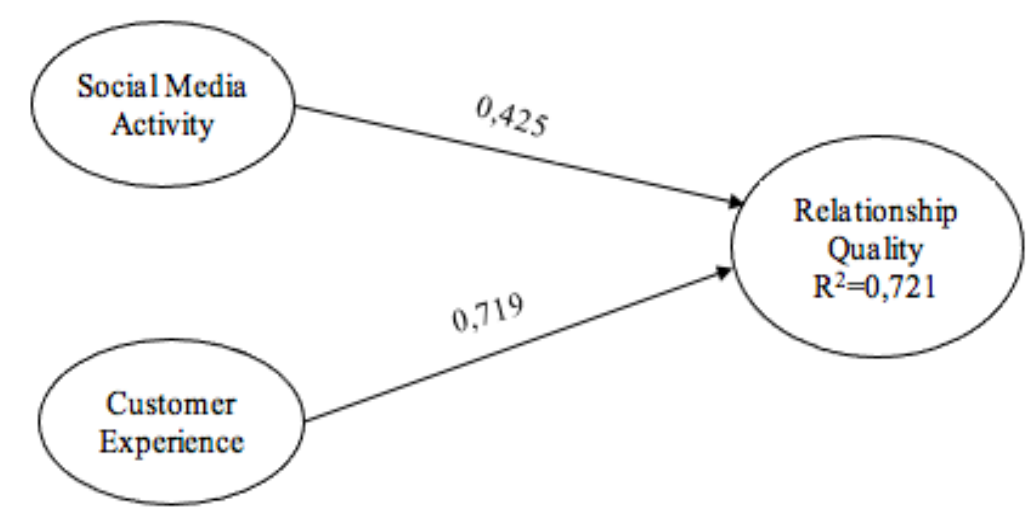

Gambar 1. Model Hasil Penelitian

Penelitian ini menemukan hasil yang konsisten dengan hasil penelitian rujukan oleh Wibowo (2021) bahwa Social Media Activity dan Customer Experience merupakan faktor yang membangun Relationship Quality. Customer Experience merupakan faktor yang paling besar mempengaruhi Relationship Quality. Nasabah merasakan (sense) pengalaman positif selama mengakses sosial media Astra Life dan mereka merasasakan 
(sense) ketertarikan untuk dapat terlibat dalam komunikasi sosial media Astra Life. Nasabah juga memiliki pemikiran (think) bahwa Astra Life mampu mengomunikasikan produk secara emosional dan relevan sehingga merangsang keingintahuan mereka. Bagi nasabah sosial media Astra Life menjadi media untuk menghubungkan (relate) mereka dengan orang lain yang memiliki gaya hidup dan kebutuhan asuransi yang sama sehingga nasabah dapat merasakan kesamaan hubungan dengan pelanggan lain melalui media sosial Astra Life. Hal tersebut yang pada akhirnya membuat nasabah bertindak dan bersikap (act) positif dalam kegiatan sosial media Astra Life; menyukai unggahan, membagikan unggahan, memberikan komentar posiitif, hingga bertransaksi melalui sosial media Astra Life. Hal itu sejalan dengan penelitian yang dilakukan oleh Shamsan \& Otieno (2014) yang menyatakan bahwa strategi public relations idealnya dapat disesuaikan dengan pola dan tren komunikasi sosial agar dapat membangun kualitas hubungan dengan publik secara relevan yang dilakukan melalui media sosial.

Dalam penelitian ini aktivitas sosial media Astra Life juga menjadi faktor berikutnya yang menentukan kualitas hubungan (Relationship Quality). Nasabah menganggap bahwa aktifitas sosial media Astra Life yang menarik dengan konten informasi yang relevan, membuat mereka merasa dilibatkan dalam aktivitas sosial media tersebut. Aktivitas sosial media Astra Life juga dinilai aktif dan interaktif sehingga nasabah merasakan hubungan relasional Astra Life dengan para nasabah yang menjadi pengikut sosial medianya.

Hasil penelitian ini menunjukkan bahwa Social Media Activity dan Customer Experience dapat digunakan sebagai pendekatan strategi PR dalam membangun Relationship Quality Astra Life. Relationship Quality Astra Life dapat dioptimalkan melalui aktivitas media sosial Astra Life sebagai communication and relationship platform serta melalui pengalaman positif nasabah selama terlibat dengan kegiatan media sosial Astra Life. Aktifitas social media tersebut juga harus ditunjang dengan keyakinan nasabah bahwa kegiatan sosial media Astra Life dapat dipercaya sebagai upaya untuk memberikan layanan dan pengalaman positif terbaik dalam bertransaksi dan berkomunikasi dengan nasabahnya.

\section{Kesimpulan}

Berdasarkan hasil penelitian Social Media Activity dan Customer Experience dalam membentuk Relationship Quality pada PT Asuransi Jiwa Astra (Astra Life) dapat 
ditarik kesimpulan bahwa dalam membangun kualitas hubungan public relations dapat menggunakan Social Media Activity maupun Customer Experience sebagai pendekatan strategisnya. Semakin aktif dan interaktif kegiatan sosial media dan semakin positif pengalama nasabah dalam mengakses sosial media Astra Life akan semakin menguatkan Relationship Quality Astra Life dengan nasabah. Sebaliknya Apabila Astra Life tidak mampu menciptakan aktivitas sosial media yang kondusif, dan tidak mampu menciptakan pengalaman positif bagi nasabah maka Relationship Quality Astra Life dengan nasabahnya menjadi tidak berkualitas.

Agar dapat menciptakan Customer Experience yang positif, Astra Life harus membuat nasabahnya selalu tertarik untuk dapat terlibat dalam komunikasi sosial medianya. Astra Life juga harus tetap mampu mengomunikasikan produk secara emosional dan relevan sehingga keingintahuan tahuan nasabah akan produk dan layanan Astra Life dapat ditingkatkan. Sosial media Astra Life juga harus konsisten memelihara relevansi konten sosial medianya, dalam hal ini sosial media Astra Life dapat dijadikan sebagai community medium antar nasabah yang memiliki gaya hidup dan kebutuhan asuransi yang sama sehingga mereka dapat saling bertukar pengalaman dan saling membagikan pengalamannya di media sosial. Aktivitas sosial media Astra Life juga harus secara aktif dan persuasif untuk melibatkan nasabah dalam interaksi sosial medianya sehingga komunikasi dialogis dua arah dapat mengarah pada terbentuknya mutual relationship bagi Astra Life dengan para nasabahnya.

Penelitian memiliki keterbatasan temuan yang hanya berlaku pada PT Asuransi Jiwa Astra (Astra Life) sehingga penelitian selanjutnya dapat meneliti potensi Social Media Activity dan Customer Experience dalam membangun Relationship Quality pada industri lainnya yang sejenis sehingga dapat diperoleh temuan penelitian yang beragam di bidang komunikasi dan public relations.

\section{Daftar Pustaka}

Bhargave, D. (2010). The use of Internet in public relations and its impact on the practice: A New Zealand perspective. AUT University. https://openrepository.aut.ac.nz/bitstream/handle/10292/1052/BhargavaD.pdf;se q uence $=3$

Boonlertvanich. (2019). Service quality, satisfaction, trust, and loyalty: the moderating role of main-bank and wealth status. International Journal of Bank Marketing, 
37(1), 278-302. https://doi.org/10.1108/IJBM-02-2018-0021

Cakici et al. (2019). The impact of perceived price justice and satisfaction on loyalty: the mediating effect of revisit intention. Tourism Review, 74(3), 443-462. https://doi.org/10.1108/TR-02-2018-0025

Carr, C.T.; Hayes, R. A. (2015). Social Media: Defining, Developing, and Divining. Atl. J. Commun, 23, 46-65.

Chen, S. C., \& Lin, C. P. (2015). The impact of customer experience and perceived value on sustainable social relationship in blogs: An empirical study. Technological Forecasting and Social Change, 96, 40-50. https://doi.org/10.1016/j.techfore.2014.11.011

Cheng, J.-C. (2019). Social media and Public Relations Ju-Chieh Cheng ENG103 Section 3 Date of Submission: 29. May.

Gardiola Fitri, Alysha, dan Kurnia. (2020). Penggunaan Dan Pemenuhan Kebutuhan Pemirsa Drama Serial Sebagai Upaya Mempertahankan Tayangan Program Televisi India di ANTV. Ganaya: Jurnal Ilmu Sosial Dan Humaniora, 3(2), 300313.

Grunig, J., \& Hung-Baesecke, F. (2015). The effect of relationships on reputation and reputation on relationships. In Ki, E.-Y., Kim, J.-N. and Ledingham, J.(Eds), Public Relations as Relationship Management: A Relational Approach to the Study and Practice of Public Relations, 2nd ed., Routledg.

Hsu, H.Y.; Tsou, H.-T. (2011). Understanding customer experiences in online blog environments. Int. J. Inf. Manag, 31, 510-523.

Izogo, E, E., Jayawardhena, C., and Kalu, U, O, A. (2018). Examining Customers' Experience With the Nigerian Bank Verification Number (BVN) Policy From The Perspective of A Dual-Lens Theory. International Journal of Emerging, 13(4), 709-730.

Juditha, C. (2017). Memahami Struktur Jaringan Media Sosial sebagai Cara Strategis Periklanan di Era Ekonomi Digital. Jurnal Pekommas, 2(1), 99-114.

Kim, H. W., Chan, H. C., \& Gupta, S. (2015). Social media for business and society. Asia Pacific Journal of Information Systems, 25(2), 329-336.

Kurniawati, D., \& Arifin, N. (2015). Strategi pemasaran melalui media sosial dan minat beli mahasiswa. JURNAL SIMBOLIKA: Research and Learning in Communication Study, 1(2). 
Martinelli. (2020). Public Relations Basics. In The Evolving World Of Public Relations: Beyond The Press Release. https://psu.pb.unizin.org/comm370/chapter/chapter3-the-world-of-public-relations/

Reitz, A. (2012). Social Media's Function in Organizations: A Functional Analysis Approach. Global Media Journal: Canadian Edition, 5(2).

Shamsan, R. M., \& Otieno, M. (2014). Effects of Strategic Public Relations on Organization Performance: A Case Study of Kenya Red Cross Society. International Journal of Scientific and Research Publications, 5(1), 2250-3153. Www.ijsrp.org

Wibowo, A., Chen, S. C., Wiangin, U., Ma, Y., \& Ruangkanjanases, A. (2021). Customer Behavior as an Outcome of Social Media Marketing: The Role of Social Media Marketing Activity and Customer Experience. Sustainability, 13(1), 1-18.

Zhang, Y., Fang, Y., Wei, K. K., Ramsey, E., McCole, P., \& Chen, H. (2011). Repurchase intention in $\mathrm{B} 2 \mathrm{C}$ e-commerce-A relationship quality perspective. Information \& Management, 48(6), 192-200. 